\title{
Determinants of skilled attendance for delivery in Northwest Ethiopia: a community based nested case control study
}

\author{
Zelalem Birhanu Mengesha ${ }^{*}$, Gashaw Andargie Biks ${ }^{2}$, Tadesse Awoke Ayele ${ }^{3}$, Gizachew Assefa Tessema ${ }^{1}$ \\ and Digsu Negesse Koye ${ }^{3}$
}

\begin{abstract}
Background: The fifth Millennium Development Goal calls for a reduction of maternal mortality ratio by $75 \%$ between 1990 and 2015. A key indicator to measure this goal is the proportion of births attended by skilled health personnel. The maternal mortality ratio of Ethiopia is 676 deaths per 100,000 live births. Skilled birth attendance is correlated with lower maternal mortality rates globally and in Sub-Saharan Africa. However, the proportion of births with a skilled attendant is only $10 \%$ in Ethiopia. Therefore identifying the determinants of skilled attendance for delivery is a priority area to give policy recommendations.
\end{abstract}

Methods: A community based nested case control study was conducted from October 2009 - August 2011 at the University of Gondar health and demographic surveillance systems site located at Dabat district, Northwest Ethiopia. Data were obtained from the infant mortality prospective follow up study conducted to identify the determinants of infant survival. A pretested and structured questionnaire via interview was used to collect data on the different variables. Logistic regression analysis was used to identify the determinants of skilled birth attendance. Strength of the association was assessed using odds ratio with $95 \% \mathrm{Cl}$.

Results: A total of 1065 mothers ( 213 cases and 852 controls) were included in the analysis. Among the cases, $166(77.9 \%)$ were from urban areas. More than half (54\%) of the cases have secondary and above level of education. Secondary and above level of education $[\mathrm{AOR}(95 \% \mathrm{Cl})=2.8(1.29,3.68)]$ and urban residence $[\mathrm{AOR}(95 \% \mathrm{Cl})=8.8(5.32$, 14.46)] were associated with skilled attendance for delivery. Similarly, women who had ANC during their pregnancy four or more times $[\mathrm{AOR}(95 \% \mathrm{Cl})=2.8(1.56,4.98)]$ and who own TV $[\mathrm{AOR}(95 \% \mathrm{Cl})=2.5(1.32,4.76)]$ were more likely to deliver with the assistance of a skilled attendant.

Conclusions: Women's education, place of residence, frequency of antenatal care visit and ever use of family planning were found to be determinants of skilled birth attendance. Encouraging women to complete at least secondary education and to have antenatal care frequently are important to increase skilled attendance during delivery.

Keywords: Determinant, Skilled birth attendance, Ethiopia

\section{Background}

One of the eight Millennium Development Goals (MDGs) adopted by United Nations in September 2000 was improving maternal health. Despite proven interventions that could prevent disability or death during pregnancy and childbirth, maternal mortality remains a major burden

\footnotetext{
* Correspondence: zelalem78@gmail.com

'Department of Reproductive Health, Institute of Public Health, University of Gondar, Gondar, Ethiopia

Full list of author information is available at the end of the article
}

in many developing countries. The Maternal Mortality Ratio (MMR), the most common measure of maternal health, continues to be a major challenge in Africa compared to performance in the rest of the world [1,2].

In 2008, of the estimated 358000 maternal deaths worldwide, developing countries accounted for 99\% (355 000). Nearly three fifths of the maternal deaths (204 000) occurred in the Sub- Saharan Africa (SSA) region alone, followed by South Asia (109 000). Together the two regions accounted for $87 \%$ of such deaths globally.

\section{Biomed Central}


Southern Asia has made steady progress, with a 53\% decline in maternal mortality between 1990 and 2008. In contrast, the ratio has fallen by only $26 \%$ in Sub-Saharan Africa, though evidence suggests that progress has picked up speed since 2000 . More than $50 \%$ of all maternal deaths were in only six countries in 2008 (India, Nigeria, Pakistan, Afghanistan, Ethiopia, and the Democratic Republic of Congo) $[1,3,4]$. According to the 2011 Ethiopian Demographic and Health Survey (EDHS) report, MMR was 676 deaths per 100,000 live births. Maternal deaths represent $30 \%$ of all deaths to women age 15-49, compared with $21 \%$ in the 2005 EDHS and 25\% in the 2000 EDHS [5-7].

The fifth MGD calls for a reduction in the maternal mortality ratio by $75 \%$ between 1990 and 2015 . A key indicator to measure this goal is the proportion of births attended by skilled health personnel [8]. A skilled birth attendant is an accredited health professional - such as a midwife, doctor or nurse - who has been educated and trained to proficiency in the skills needed to manage normal (uncomplicated) pregnancies, childbirth and the immediate postnatal period, and in the identification, management and referral of complications in women and newborns [9]. A skilled health professional can administer interventions to prevent and manage life-threatening complications, such as heavy bleeding, or refer the patient to a higher level of care when needed [10].

The presence of a trained health-care worker during delivery is crucial in reducing maternal deaths whereby estimates between $13 \%-33 \%$ of maternal deaths could be averted by the presence of a skilled birth attendant [11]. Skilled birth attendance is also correlated with lower maternal mortality rates in SSA [12]. Proportion of deliveries attended by skilled health personnel in developing regions overall rose from $55 \%$ in 1990 to $65 \%$ in 2009 . However, the proportion in Ethiopia is very much lower than SSA. Even for women who have access to the services, the proportion of births with a skilled attendant is very low. Skilled care at delivery is usually provided at health facilities (hospitals and health centers) in Ethiopia. One of the targets of the Ethiopian reproductive health strategy is to increase the proportion of births attended by skilled health personnel either at home or in a facility to $60 \%$ by 2015 [13]. However, the 2011 EDHS revealed that only $10 \%$ of births were delivered by the assistance of a skilled attendant [5].

Therefore identifying the determinants of skilled attendance for delivery is a priority area to give policy recommendations.

\section{Methods}

A community based nested case control study was conducted from October 2009-August 2011 at the University of Gondar health and demographic surveillance systems site which is located at Dabat district, Northwest Ethiopia. Dabat district is located about $75 \mathrm{kms}$ away from Gondar town. It has an area of $1,199.15 \mathrm{~km}^{2}$ and had an estimated total population of 145,458 ( $89 \%$ live in rural area). Altitude ranges from 1000-2600 m above sea level. Agriculture is the backbone of their economy. The district has a total of 29 functioning health institutions (27 health posts and 2 health centers).

The demographic survey site has three ecological regions including high, mid and lowland. Baseline data collection for the research center was started in November 1996 and subsequent vital events (birth, death, migration) registration has been continued since August 2004. According to the second baseline survey conducted in August 2007, the total numbers of households were about 9,334 and the total population of the center was 46,165 . Antenatal care coverage and prevalence of contraceptive were found to be $51 \%$ and $19.2 \%$ respectively. Only $7.2 \%$ of deliveries took place in health institutions and $7.85 \%$ of the births were attended by skilled professionals [14].

All mothers with second and third trimester pregnancy were registered and on follow up from October 2009 to August 2011 for infant mortality prospective study. The population for this study consisted of sampled cases and controls of women who gave birth during the follow up period. Cases were women who gave birth by the help of skilled attendants while controls were those who gave birth by the help of traditional birth attendants, relatives or health extension workers. All cases and a random sample of controls were taken from the deliveries, which took place in the study period.

Data were collected via interview using pretested and structured questionnaire. The questionnaire was prepared in English, translated to Amharic and then translated back to English to check for consistency. Six female data collectors working at the research site were recruited. Training was given to the data collectors for one day about the objective, relevance of the study, confidentiality of information, participant's right, pre-test, informed consent and techniques of interview.

The sample size was calculated using Epi info version 3.3.2.0 by considering the following assumptions: the proportion of urban women among the controls 23.9\% [15], $95 \% \mathrm{CI}, 80 \%$ power and case to control ratio of $1: 4$ to detect an odds ratio of 2.0. The total sample size was 510 (102 cases and 408 controls). There were 1752 pregnant women recruited for the prospective infant mortality study. Among these, 213 (12.2\%) delivered with the assistance of a skilled attendant. Since there were more participants for the study from the follow up database, we took all the cases (213) and a random sample of controls (852 out of the 1539) for final analysis.

Before the actual data collection, pretest was conducted in adjacent kebeles to ensure the validity of the 
survey tool. The supervisors and the principal investigator made frequent checks on the data collection process to ensure the completeness and consistency of the gathered information.

Data were entered and cleaned using EPI info version 6 statistical software and exported to SPSS version 16 statistical packages for analysis. Frequencies, proportion and summary statistics were used to describe the study population in relation to relevant variables.

\section{Hypothesis}

Factors affecting utilization of skilled attendants are the same in Dabat and elsewhere in Ethiopia. These are parity, having ANC, women's and their husbands educational status, occupational status, having TV and Radio, urban residence, history of family planning use, younger age, economic status, knowledge about danger signs of pregnancy, availability and attitude towards health professionals, husband's approval and involvement.

Bivariate and multivariate analyses were carried out to see the effect of each independent variable on the dependent variable. Odds ratio with $95 \% \mathrm{CI}$ was computed to assess the strength of the association and statistical significance. P-value less than 0.05 was used to declare statistical significance in the multivariate analysis.

Ethical clearance was obtained from the Institution Review Board of the University of Gondar. The purpose and importance of the study were explained to the participants. Data were collected after full informed verbal consent is obtained and confidentiality of the information has been maintained throughout by excluding names as identification in the questionnaire and keeping their privacy during the interview by interviewing them alone.

\section{Results}

Socio demographic characteristics of the participants

A total of 1065 mothers (213 cases and 852 controls) were included in the analysis. Among the cases, 166 (77.9\%) were from urban areas. More than half (54\%) of the cases have secondary and above level of education. Around 89 and $98 \%$ of the controls did not have radio and television respectively. Orthodox religion followers accounted $94.4 \%$ of the case and $98.9 \%$ of the controls. Married participants accounted $83.6 \%$ and $94.6 \%$ among the cases and controls respectively. One hundred eleven (52.1\%) of the cases and 770 (90.4\%) of the controls were housewives by occupation. Secondary and above level of education was attained by $94(44.1 \%)$ among the cases' husbands. Ninety nine (46.5\%) and $764(89.7 \%)$ of the cases' and controls' husbands were farmers [Table 1].

\section{Obstetric characteristics of the study participants}

One hundred fifty two (71\%) of the cases had ANC follow up but $81.3 \%$ of the controls didn't have. Nearly
Table 1 Socio demographic characteristics of the study participants, Dabat DSS site, Northwest Ethiopia, 2011 ( $n=1065)$

\begin{tabular}{|c|c|c|c|}
\hline \multirow[t]{2}{*}{ Variables } & \multirow[t]{2}{*}{ Category } & \multicolumn{2}{|c|}{ Skilled birth attendance } \\
\hline & & Cases (\%) & Controls (\%) \\
\hline \multirow[t]{2}{*}{ Residence } & Urban & $166(77.9)$ & $87(10.2)$ \\
\hline & Rural & $47(22.1)$ & $765(89.8)$ \\
\hline \multirow[t]{2}{*}{ Own Radio } & Yes & $113(53.1)$ & $97(11.4)$ \\
\hline & No & $100(46.9)$ & $755(88.6)$ \\
\hline \multirow[t]{2}{*}{ Own TV } & Yes & $66(31.0)$ & $18(2.1)$ \\
\hline & No & $147(69.0)$ & $834(97.9)$ \\
\hline \multirow[t]{3}{*}{ Maternal education } & $\begin{array}{l}\text { Can not read } \\
\text { and write }\end{array}$ & $69(32.4)$ & $673(79.0)$ \\
\hline & Primary & 29 (13.6) & $106(12.4)$ \\
\hline & Secondary and above & $115(54.0)$ & $73(8.6)$ \\
\hline \multirow[t]{2}{*}{ Religion } & Orthodox & $201(94.4)$ & $843(98.9)$ \\
\hline & Muslim & $12(5.6)$ & $9(1.1)$ \\
\hline \multirow[t]{2}{*}{ Marital status } & Married & 178 (83.6) & $806(94.6)$ \\
\hline & $\begin{array}{l}\text { Single/widowed/ } \\
\text { separated }\end{array}$ & $35(16.4)$ & $46(5.4)$ \\
\hline \multirow{4}{*}{$\begin{array}{l}\text { Maternal } \\
\text { occupation }\end{array}$} & Farmer & $2(.9)$ & $13(1.5)$ \\
\hline & Own business & $51(23.9)$ & $20(2.3)$ \\
\hline & House wife & $111(52.1)$ & $770(90.4)$ \\
\hline & Others & $49(23.0)$ & $49(5.8)$ \\
\hline \multirow[t]{3}{*}{ Maternal age } & $\leq 19$ & $18(8.5)$ & $102(12.0)$ \\
\hline & $20-34$ & $155(72.8)$ & $597(70.1)$ \\
\hline & $\geq 35$ & $40(18.8)$ & $153(18.0)$ \\
\hline \multirow[t]{3}{*}{ Husband education } & $\begin{array}{l}\text { Can not read } \\
\text { and write }\end{array}$ & $65(30.5)$ & $534(62.7)$ \\
\hline & Primary education & $54(25.4)$ & $246(28.9)$ \\
\hline & Secondary and above & $94(44.1)$ & $72(8.5)$ \\
\hline \multirow[t]{4}{*}{ Husband occupation } & Student & $4(1.9)$ & $29(3.4)$ \\
\hline & Farmer & $99(46.5)$ & $764(89.7)$ \\
\hline & own business & $50(23.5)$ & $32(3.8)$ \\
\hline & Others & $60(28.2)$ & $27(3.2)$ \\
\hline
\end{tabular}

two third (61.5\%) of the cases ever used family planning methods and only $19.8 \%$ of the controls ever use family planning. Both the cases and controls had almost similar history of abortion and still birth. Three quarters (76.8\%) of the controls delivered at home but $90.6 \%$ of the cases had delivered at health institutions. Nearly one third of the cases $(37.1 \%)$ had no history of prior pregnancy but only $15.4 \%$ of the controls had more than one pregnancy history [Table 2].

\section{Determinants of skilled birth attendance}

As clearly depicted on the multivariate logistic regression, urban residence, having TV, having ANC follow up, ever use of family planning and secondary and above 
Table 2 Obstetric histories of the participants at Dabat DSS site, Northwest Ethiopia, 2011 ( $n=1065)$

\begin{tabular}{llrr}
\hline Variable & Category & \multicolumn{2}{c}{ Skilled birth attendance } \\
\cline { 2 - 4 } & & \multicolumn{1}{c}{ Cases } & Controls \\
\hline ANC follow up & Yes & $152(71.4)$ & $159(18.7)$ \\
& No & $61(28.6)$ & $693(81.3)$ \\
Ever use of family & Yes & $131(61.5)$ & $169(19.8)$ \\
planning & No & $82(38.5)$ & $683(80.2)$ \\
History of abortion & Yes & $11(5.2)$ & $39(4.6)$ \\
& No & $202(94.8)$ & $813(95.4)$ \\
History of still births & Yes & $9(4.2)$ & $25(2.9)$ \\
& No & $204(95.8)$ & $827(97.1)$ \\
Place of delivery & Home & $16(7.5)$ & $654(76.8)$ \\
& Hospital & $42(19.7)$ & $0(0)$ \\
& Health center/clinic & $151(70.9)$ & $3(0.4)$ \\
& Other government & $4(1.9)$ & $195(22.9)$ \\
& health institutions & & \\
& 1 & $79(37.1)$ & $131(15.4)$ \\
& 2-4 & $88(41.3)$ & $376(44.1)$ \\
& $\geq 5$ & $46(21.6)$ & $345(40.5)$ \\
\hline
\end{tabular}

level of maternal education were significantly and independently associated with skilled birth attendance.

Accordingly, women from urban areas were 8.8 times $[$ AOR $(95 \% \mathrm{CI})=8.8(5.32,14.46)]$ more likely to have skilled birth attendance as compared to rural women. Those women who own TV were 2.5 times [AOR $(95 \% \mathrm{CI})=2.5(1.32,4.76)]$ more likely to utilize skilled birth attendance as compared to their counter parts.

Having ANC follow up was found to be an important determinant of skilled birth attendance in which women who had four or more visits were 2.8 times [AOR (95\% $\mathrm{CI})=2.8(1.56,4.98)]$ more likely to have skilled birth attendance as compared to those who didn't have follow up.

Regarding family planning use, ever users were 1.71 times [AOR $(95 \% \mathrm{CI})=1.71(1.09,2.69)]$ more likely to have skilled birth attendance as compared to those who didn't. Women with secondary and above education were about 2.18 times [AOR $(95 \% \mathrm{CI})=2.18(1.29,3.68)$ ] more likely to have skilled attendance than those with no formal education. However, having radio, husband's educational status, marital status, maternal age and husband's occupation were not significantly associated with skilled birth attendance [Table 3].

\section{Discussion}

Majority of deaths from obstetric complications are preventable and that every pregnancy faces risk which may not always be detected through the risk assessment approach during ANC [15]. Delivery assisted by skilled providers is the most important proven intervention in reducing maternal mortality and one of the MDG indicators to track national effort towards safe motherhood [16]. However, the proportion of births attended by skilled health personnel did not increase substantially from 2000 to 2011 in Ethiopia i.e. it increased from $5 \%$ to $10 \%$. This is also reflected by the high maternal mortality ratio observed in the 2011 EDHS [5]. In this study, a number of socio demographic and other factors were found to have a significant influence on the use of skilled care at delivery. These include residence, maternal education, owning TV and number of ANC visits.

Antenatal care with a skilled provider is one of the interventions that reduce maternal mortality. Because it allows early detection of obstetric complications and gives an opportunity to influence women's decision to have a skilled attendance during child birth. WHO recommends at least four visits starting from the first trimester. Interestingly, antenatal care was a significant positive determinant of skilled attendance during delivery only for those women who attended four or more times. This finding is consistent with other studies done in Tanzania and Cambodia $[17,18]$.

This study showed the importance of women's education for the utilization of skilled birth attendance. Women with secondary and above education were about two times more likely to have skilled attendance than those with no formal education. This finding is in line with most maternal and child health studies conducted in developing countries $[15,19,20]$. The effect of education on the use of skilled birth attendance can be explained in various ways. Educated women have higher level of health awareness and greater knowledge of available health services. They have also improved ability to afford the cost of health care, and their enhanced level of autonomy results in improved ability and freedom to make health-related decisions, including choice of maternal services to use [21,22]. It is also likely that educated women will seek higher quality services and have greater ability to use health care inputs that offer better care [22]. Better educated women are more likely to have knowledge of the long-term benefits of the utilization of skilled maternity care services for both mother and babies compared to less educated women [23].

At the community level, urban residence was found to be associated with increased utilization of skilled birth attendants. This finding is in agreement with previous studies in sub Saharan Africa [15,24] and elsewhere $[25,26]$ which have reported a significantly higher use of services in urban compared to rural areas. The reason might be urban women tend to have better access to health facilities and other promotional activities that are usually urban based. Moreover, rural women are more 
Table 3 Unadjusted and adjusted odds ratios (OR) and $95 \%$ confidence intervals $(\mathrm{CI})$ of determinants of skilled birth attendance at Dabat DSS site, Northwest Ethiopia, $2011(\mathrm{n}=1065)$

\begin{tabular}{|c|c|c|c|c|c|}
\hline \multicolumn{2}{|l|}{ Determinants } & \multirow{2}{*}{$\begin{array}{l}\text { Cases } \\
166(77.9)\end{array}$} & \multirow{2}{*}{$\begin{array}{l}\text { Controls } \\
87(10.2)\end{array}$} & \multirow{2}{*}{$\begin{array}{l}\text { Crude OR }(\mathbf{9 5} \% \mathbf{C l}) \\
31.1(20.96,45.98)\end{array}$} & \multirow{2}{*}{$\begin{array}{l}\text { Adjusted OR (95\%Cl } \\
8.8(5.32,14.46)\end{array}$} \\
\hline Residence & Urban & & & & \\
\hline & Rural & $47(22.1)$ & 765 (89.8) & 1 & 1 \\
\hline \multirow[t]{2}{*}{ Own radio } & Yes & $113(53.1)$ & $97(11.4)$ & $8.8(6.25,12.38)$ & \\
\hline & No & $100(46.9)$ & 755 (88.6) & 1 & \\
\hline \multirow[t]{2}{*}{ Own TV } & Yes & $66(31.0)$ & $18(2.1)$ & $20.8(12.004,36.052)$ & $2.5(1.32,4.76)$ \\
\hline & No & $147(69.0)$ & $834(97.9)$ & 1 & 1 \\
\hline \multirow[t]{3}{*}{ ANC follow up } & No & $152(71.4)$ & $159(18.7)$ & 1 & 1 \\
\hline & $1-3$ & $61(28.6)$ & $693(81.3)$ & $5.9(3.92,8.82)$ & $1.6(0.94,2.73)$ \\
\hline & $\geq 4$ & $152(71.4)$ & $159(18.7)$ & $20.2(13.06,31.07)$ & $2.8(1.56,4.98)$ \\
\hline \multirow[t]{2}{*}{ Family planning use } & Yes & $131(61.5)$ & 169 (19.8) & $6.5(4.67,8.92)$ & $1.71(1.09,2.70)$ \\
\hline & No & $82(38.5)$ & $683(80.2)$ & 1 & 1 \\
\hline \multirow[t]{3}{*}{ Husband's education } & Illiterate & $65(30.5)$ & $534(62.7)$ & 1 & \\
\hline & Primary & $54(25.4)$ & $246(28.9)$ & $1.8(1.22,2.67)$ & \\
\hline & Secondary and above & $94(44.1)$ & $72(8.5)$ & $10.7(7.19,16.01)$ & \\
\hline \multirow[t]{3}{*}{ Maternal education } & Illiterate & $69(32.4)$ & $673(79.0)$ & 1 & 1 \\
\hline & Primary & $29(13.6)$ & $106(12.4)$ & $2.7(1.65,4.31)$ & $1.23(0.67,2.27)$ \\
\hline & Secondary and above & $115(54.0)$ & $73(8.6)$ & $15.4(10.47,22.56)$ & $2.18(1.29,3.68)$ \\
\hline \multirow[t]{2}{*}{ Marital status } & Married & 178 (83.6) & $806(94.6)$ & $0.3(0.18,0.46)$ & \\
\hline & Single/Widowed/Separated & $35(16.4)$ & $46(5.4)$ & 1 & \\
\hline \multirow[t]{3}{*}{ Maternal age } & $\leq 19$ & $18(8.5)$ & $102(12.0)$ & $0.7(0.37,1.24)$ & \\
\hline & $20-34$ & $155(72.8)$ & $597(70.1)$ & $0.9(0.67,1.47)$ & \\
\hline & $\geq 34$ & $40(18.8)$ & $153(18.0)$ & 1 & \\
\hline \multirow[t]{4}{*}{ Husbands occupation } & Student & $4(1.9)$ & $29(3.4)$ & 1 & \\
\hline & Farmer & $99(46.5)$ & $764(89.7)$ & $0.1(0.02,0.19)$ & \\
\hline & Own business & $50(23.5)$ & $32(3.8)$ & $0.1(0.04,0.10)$ & \\
\hline & Others & $60(28.2)$ & $27(3.2)$ & $0.7(0.37,1.33)$ & \\
\hline \multirow[t]{3}{*}{ Parity } & 1 & $79(37.1)$ & $131(15.4)$ & $4.5(2.99,6.85)$ & \\
\hline & $2-4$ & $88(41.3)$ & $376(44.1)$ & $1.8(1.19-2.58)$ & \\
\hline & $\geq 5$ & $46(21.6)$ & $345(40.5)$ & 1 & \\
\hline \multirow[t]{2}{*}{ Religion } & Orthodox & $201(94.4)$ & $843(98.9)$ & $0.2(0.07,0.43)$ & \\
\hline & Muslim & $12(5.6)$ & $9(1.1)$ & 1 & \\
\hline
\end{tabular}

readily influenced by traditional practices that run contrary to modern health care [27].

Studies have shown that exposure to mass media promotes health-related behaviors including reproductive health services $[28,29]$. In line with this, women who own TV were more likely to utilize skilled birth attendance as compared to those who do not have. A study done in Bolivia also suggested that mass media are effective in information dissemination which fosters inter-personnel communication that could facilitate behavioral changes allowing for the adoption of new/different behaviors [30].

As a limitation, unmeasured independent factors may have important impacts on the outcomes that could not be captured in this study. Specifically, economical status, knowledge of danger signs, attitude towards health professionals and husbands' approval and involvement. This is because of the nature of the study that a secondary analysis of a prospective infant mortality study is done to identify the determinants of skilled birth attendance utilization.

\section{Conclusions}

The results of this study showed that the determinants of skilled attendance during child birth are mostly sociodemographic and service related. The major factors identified include women's education, place of residence, 
frequency of antenatal care service, ever use of family planning and having Television. Encouraging women to complete at least secondary school and teaching/ encouraging women to have antenatal care frequently are important to increase skilled attendance during delivery. Researchers should also explore effective ways of increasing service utilization among less educated and uneducated women, women in rural areas and women who are not taking ANC.

\section{Competing interests}

The authors declare that they have no competing interests.

\section{Authors' contributions}

ZB, GA, DN, TA, and GA participated in all steps of the study from its commencement to write up. They have reviewed and approved the submission of the manuscript.

\section{Acknowledgments}

We would like to acknowledge the University of Gondar and World Health Organization for financial support. We wish to acknowledge Dabat HDSS supervisors and data collectors for their support and collaboration throughout the project. Finally, our deepest gratitude goes to the study participants.

\section{Author details}

'Department of Reproductive Health, Institute of Public Health, University of Gondar, Gondar, Ethiopia. ${ }^{2}$ Department of Health Service Management and Health Economics, Institute of Public Health, University of Gondar, Gondar, Ethiopia. ${ }^{3}$ Department of Epidemiology and Biostatistics, Institute of Public Health, University of Gondar, Gondar, Ethiopia.

Received: 10 August 2012 Accepted: 9 February 2013

Published: 12 February 2013

\section{References}

1. United Nations: The Millennium Development Goals Report. New York: United Nations; 2011

2. UNDP, The African Development Bank, The United Nations Economic Commission for Africa, The African Union Commission: Assessing Progress in Africa toward the Millennium Development Goals.: UNDP, The African Development Bank, The United Nations Economic Commission for Africa, The African Union Commission; 2011.

3. WHO: Trends in maternal mortality: 1990 to 2008. Geneva: WHO, UNICEF, UNFPA,The World Bank; 2010.

4. Hogan MC, Foreman KJ, Naghavi M, Ahn SY, Wang M, Makela SM, Lopez AD, Lozano R, Murray CJL: Maternal mortality for 181 countries, 1980-2008: a systematic analysis of progress towards Millennium Development Goal 5. Lancet 2010, 375(9726):1609-1623.

5. Central Statistical Agency and ICF International: Ethiopian Demographic and Health Survey. Addis Ababa, Ethiopia: Central Statistical Agency and ICF International; 2011.

6. Central Statistical Agency and ICF International: Ethiopia Demographic and Health Survey. Addis Ababa: Central Statistical Agency and ORC Macro; 2005.

7. Central Statistical Authority and ORC Macro: Ethiopia Demographic and Health Survey. Addis Ababa: Central Statistical Authority and ORC Macro; 2000.

8. Sachs J, McArthur J: The Millennium Project: a plan for meeting the Millennium Development Goals. Lancet 2005, 365(9456):347-353.

9. WHO: Health services coverage statistics. [http://www.who.int/healthinfo/ statistics/indbirthswithskilledhealthpersonnel/en/].

10. WHO: Making pregnancy safer: The critical role of the skilled attendant. Geneva: WHO, ICM, FIGO; 2004.

11. Graham W, Bell J, Bullough W: Can skilled attendance reduce maternal mortality in developing countries? Stud HSO\&P 2001, 17:97-129.

12. Buor D, Bream K: An analysis of the determinants of maternal mortality in Sub-Saharan Africa. J Womens Health 2004, 13(8):926-938.

13. Federal Democratic Republic of Ethiopia Ministry of Health: National Reproductive Health Strategy 2006-2015. Addis Ababa, Ethiopia: Federal Democratic Republic of Ethiopia Ministry of Health; 2006.
14. Tadesse T, Getachew A, Admassu M, Kebede Y, Awoke T, Melesse T, Amsalu S, Alemu S: Demographic and Health Survey at Dabat district in Northwest Ethiopia: Report of the 2008 baseline survey. Ethiop J Health Biomed Sci 2011, 4:2-23.

15. Nigussie M, Mariam DH, Mitike G: Assessment of safe delivery service utilization among women of childbearing age in north Gondar Zone, north west Ethiopia. EthiopJHealth Dev 2004, 18(3):145-152.

16. United Nations: The Millennium Development Goals Report. New York: United Nations; 2007

17. Mpembeni RNM, Killewo JZ, Leshabari MT, Massawe SN, Jahn A, Mushi D, Mwakipa $\mathrm{H}$ : Use pattern of maternal health services and determinants of skilled care during delivery in Southern Tanzania: implications for achievement of MDG-5 targets. BMC Pregnancy Childbirth 2007, 7:29-29.

18. Yanagisawa $S$, Oum $S$, Wakai S: Determinants of skilled birth attendance in rural Cambodia. Trop Med Int Health: TM \& IH 2006, 11(2):238-251.

19. Idris SH, Gwarzo UMD, Shehu AU: Determinants of place of delivery among women in a semi-urban settlement in Zaria, northern Nigeria. Ann Afr Med 2007, 5(2):68-72.

20. Onah HE, lkeako LC, lloabachie GC: Factors associated with the use of maternity services in Enugu, southeastern Nigeria. Soc Sci Med 2006, 63(7):1870-1878.

21. Raghupathy S: Education and the use of maternal health care in Thailand. Soc Sci Med 1996, 43(4):459-471.

22. Celik Y: The socio-economic determinants of alternative sources of antenatal care in Turkey. Int J Health Plann Manage 2000, 15(3):221-235.

23. Acharya DR, Bell JS, Simkhada P, van Teijlingen ER, Regmi PR: Women's autonomy in household decision-making: a demographic study in Nepal. Reproductive health 2010, 7:15.

24. Ekele BA, Tunau KA: Place of delivery among women who had antenatal care in a teaching hospital. Acta Obstet Gynecol Scand 2007, 86(5):627-630.

25. Navaneetham K, Dharmalingam A: Utilization of maternal health care services in Southern India. Soc Sci Med 2002, 55(10):1849-1869.

26. Stupp PW, Macke BA, Monteith R, Paredez S: Ethnicity and the use of health services in Belize. J Biosoc Sci 1994, 26(2):165-177.

27. Mekonnen Y, Mekonnen A: Utilization of Maternal Health Care Services in Ethiopia. Addis Ababa, Ethiopia: Ethiopian Health and Nutrition Research Institute and ORC Macro; 2002.

28. Westoff CF, Bankole A: Mass Media and Reproductive Behavior in Pakistan, India, and Bangladesh. Calverton, Maryland USA: Macro International Inc; 1999.

29. Retherford RD, Mishra V: Media Exposure Increases Contraceptive Use, National Family health Survey Bulletin. Mumbai: International Institute for population Sciences; 1997.

30. Valente TW, Saba WP: Mass Media and Interpersonal Influence in a Reproductive Health Communication Campaign in Bolivia. Communication Research 1998, 25(1):96-124.

doi:10.1186/1471-2458-13-130

Cite this article as: Mengesha et al.: Determinants of skilled attendance for delivery in Northwest Ethiopia: a community based nested case control study. BMC Public Health 2013 13:130.

\section{Submit your next manuscript to BioMed Central and take full advantage of:}

- Convenient online submission

- Thorough peer review

- No space constraints or color figure charges

- Immediate publication on acceptance

- Inclusion in PubMed, CAS, Scopus and Google Scholar

- Research which is freely available for redistribution 